\title{
Fontes e formas para uma disciplina jurídica comunitária
}

\author{
Jorge Fontoura Nogueira*
}

Sumário: 1.A Tipologia das Normas Comunitárias; 2.Características de um Direito Comunitário.

O sentido e a abrangência de um direito comunitário em abstrato; tipologia de normas e caracteristicas da disciplina juridica ínsita aos processos de integração econômica.

O advento inexorável do Mercado Comum do Sul impõe aos meios jurídicos dos países signatários do Concerto de Assunção inadiável reflexão sobre a necessidade de uma disciplina jurídica que dê suporte às démarches político-econômicas que o projeto encerra.

Não e trata de um prodígio de lucidez antever a necessidade da criação de quadros e instâncias jurídicas, pari passu à superação das fases previstas no processo de integração que se vislumbra. Se o nível de institucionalização intergovernamental do atual momento de transição, de zona de livre comércio (ainda por fazer), à união aduaneira (parcial), não requer, a rigor, profundas inovações jurídicas, o mesmo não se pode dizer com relação ao colimado mercado comum, com a implantação das quatro liberdades que lhe são características (livre circulação de bens, serviços, pessoas e capitais), conforme preconiza o arrojado artigo $1^{\circ}$ do próprio Tratado de Assunção.

O exemplo do direito comunitário europeu é, neste momento de perplexidade e certezas precárias, de altíssima valia. A começar pelo formidável desacerto entre os direitos internos dos países-Mercosul e o Tratado de Assunção, com ̧ da mesma forma o foram, a seu tempo, o direito interno de muitos Estados europeus e o Tratado de Roma. A questão nodoal, a reavaliação do conceito de soberania e o realinhamento doutrinário sobre

* Doutor em Direito Internacional Público e professor visitante de direito das relações internacionais e direito comunitário dos Cursos de Doutorado e Mestrado do Curso de Ciências Jurídicas da U.F.P.

R. Fac. Direito, Curitiba, a.28, n.28, 1994/95, p.75-83 
a validade e eficácia do direito supranacional, é incontinenti nas pautas jurídicas comprometidas com o sucesso de implantação de estruturas comunitárias.

Usufruindo da experiência européia, podemos nos abeberar em uma conspícua e sólida doutrina, que hoje embasa a desde há muito consagrada e corriqueira disciplina jurídica "direito comunitário", presente em todos os programas de formação universitária desde a graduação.

Ao examinarmos os aspectos jurídicos do fenômeno comunitário, surge de chofre a questão basilar de precisar-se o sentido e abrangência da disciplina jurídica "direito comunitário". Não seria, como poderíamos imaginar, direito novo, uma matéria dotada de autonomia científica, nem direito internacional, nem direito interno, mas tertium genus, homogêneo e diferenciado de todo o conhecimento jurídico pré-existente. Para que se proceda tal delineamento é fundamental a definição dos tipos de normas passíveis de compor uma cogitada disciplina jurídica comunitária.

\section{A Tipologia das Normas Comunitárias}

Tomando por referencial o modelo CEE que é, grosso modo, o mesmo a ser seguido em análogos processos de integração, todo o universo referente à fenômenos comunitários subdividir-se-ia, essencialmente, em três grupos de normas jurídicas, diferenciadas a partir de suas fontes:

1) O primeiro grupo, dito direito comunitário originário, seria composto pelas normas previstas nos tratados de integração, incluindo seus eventuais protocolos modificativos ou complementares. Trata-se, a toda evidência, de normas que, enquanto inseridas em tratados geradores de obrigações recíprocas entre Estados soberanos, diriam respeito claramente ao direito internacional público, em cujo âmbito podem receber o específico tratamento e valoração. Não é sem mais razão que os primeiros estudiosos de direito comunitário são recrutados na área do direito público externo, pois a percepção para o primeiro approche com as questões jurídicas comunitárias é eminentemente de "direito das gentes". Trata-se, porém, de mero início, logo superado pelo turbilhão de demandas que se vão formulando; veja-se, por exemplo, o caso do corriqueiro particularismo dos direitos comerciais de países comunitários: o que fazer diante de títulos de 
crédito específicos de um único direito comercial, na emergência de um mercado onde circulam livremente bens, serviços, pessoas e capitais?

2) No segundo grupo de normas jurídicas atinentes a um proposto direito comunitário, de natureza derivada, teríamos aquelas que se referem ao ordenamento jurídico interno dos organismos comunitários comuns. Se algumas destas normas podem derivar do texto dos tratados, é claro que outras tantas podem emanar dos próprios organismos comunitários, no sentido de disciplinar suas atividades internas e seu funcionamento. $\mathrm{Na}$ estrutura orgânica do Mercosul, conforme o art. 9 do Tratado de Assunção, as instituições normativas são desde já o Conselho e o Grupo Mercado Comum. Do ponto de vista formal, tal normatividade representa um sistema claramente distinto daquele derivado dos tratados, destinando-se ao âmbito restrito do organismo institucional comunitário. O estudo deste segundo grupo apresenta virtualmente maior complexidade, não propriamente pelo seu ineditismo e atipia, mas pelo fato de tais normas se exprimirem através de regras interna corporis e não em relação a direitos e deveres recíprocos de sujeitos de direito internacional público. Com toda a cautela que as comparações fáceis devem engendrar, poderíamos aqui entrever, dentre outros cenários, um nítido delinear de incipiente direito administrativo intracomunitário:

3) Quanto ao terceiro grupo, teríamos as normas que legisladas pelos próprios organismos comunitários, nos limites de suas competências normativas concedidas pelos tratados institutivos e, eventualmente, protocolos complementares, destinar-se-iam a aplicar-se dentro dos territórios dos Estados comunitários.

Temos, portanto, no âmbito destas três qualidades de normas, absolutamente heterogêneas e mesmo com espaços de incidência e eficácia distintos, o complexo conformante do que pode ser designado "direito comunitário".

Claro que inúmeras questões de grande relevância jurídica vão paulatinamente se formulando, paralelamente à sedimentação de tal tipologia. As relações entre as normas jurídicas comunitárias e os ordenamentos jurídicos nacionais, é, por exemplo, tema sempre presente nos recorrentes debates jurídicos que soem ocorrer quando da implantação de estruturas comunitárias. O tema ganha especial insight quando superpomos a hipótese do conflito entre as normas comunitárias (diretivas e regulamentos, no

R. Fac. Direito, Curitiba, a.28, n.28, 1994/95, p.75-83 
modelo União Européia, decisões e resoluções, no atual modelo Mercosul), e normas nacionais posteriores e antitéticas, constitucionais ou infraconstitucionais. A recepção e a coordenação do direito comunitário vis-à-vis dos direitos internos suscitou na construção da União Européia formidável embate doutrinário, conducente, por sua vez, a formidável elaboração jurisprudencial.

Com referência ao específico tema da constitucionalidade dos tratados institutivos das Comunidades Européias, considerando a variedade dos sistemas constitucionais dos Estados envolvidos, houve um processo diversificado de adaptação e acomodação, com alguns deles introduzindo emendas idôneas a prevenir a verificação de conflitos e, outros, buscando simplesmente interpretações constitucionais benignas à supremacia do direito europeu.

Em nosso caso específico, podemos desde logo detectar uma série de conflitos potenciais entre o próprio Tratado de Assunção e a Constituição Federal. Tomando em conta que no seu processo de ratificação o referido Tratado foi exaustivamente analisado pelo Poder Legislativo, tendo inclusive passado incólume pelo crivo de duas Comissões de Constituição e Justiça, é de se acreditar que não estamos diante de um prosaico desleixo de apreciação de matéria. Daí, seria razoavelmente presumível que haveria intenção legislativa em rever, por exemplo, o art. 178 da Constituição Federal, em manifesto desacordo com a estipulação programática contida no art. 1 do Tratado de Assunção.

\section{Características de um Direito Comunitário}

O direito comunitário não é um direito sui generis, revolucionário ou gratuitamente subvertedor de convicções jurídicas seculares. Corresponde, ao contrário, à necessidade que deriva da hegemonia das idéias, impondo-se a partir de um livre querer, coordenado e coletivo, dos Estados pactuantes. São as seguintes as características que se vêm identificando na neo-disciplina:

1) Autonomia - As comunidades econômicas constituem uma inusitada ordem de relações político-econômicas entre Estados soberanos, necessitando, para a realização de suas finalidades pactícias, de um aparato 
jurídico da mesma forma inusitado. Tal aparato não pode ser vislumbrado como direito exclusivamente interno, tampouco como direito estrangeiro a ser aplicado internamente. Diante do aparecimento do novo referencial, território comunitário, sem que se tenha um direito novo, mas apenas um espaço juriśdicional de todo inovador, o direito comunitário irá conformarse autonomamente, porém sem nenhuma fundamental modificação epistemológica conducente à necessárias releituras ou reformulações da Ciência do Direito.

Já é possível afirmar-se, a partir da prática e de seu grau de desenvolvimento, que o direito comunitário europeu constitui aparato jurídico particular, distinto dos ordenamentos jurídicos nacionais e bastante em si quanto aos requisitos de sua eficácia e desenvolvimento.

2) Efeito Impositivo - As normas comunitárias possuem um caráter obrigatório e devem estar instrumentalizadas de forma a poderem se fazer impor a todos os jurisdicionáveis. O caráter acaciano deste item justifica-se pelo grande equívoco doutrinário que se tem disseminado, a partir de sofísticas leituras a propósito da existência jurídica, a cientificidade e eficácia do direito internacional público. Apesar do direito comunitário não se confundir com o direito internacional público, passando por ele é verdade, porém vindo muito mais aquém. não há como se negar a proximidades das disciplinas e, muitas vezes, seu circunstancial paralelismo. O efeito impositivo, seu caráter constritivo, representa a única segurança político-jurídica da dinâmica comunitária, garantidora da eficiência política e, por conseguinte. do contingente sucesso histórico do processo.

$\mathrm{Na}$ experiência européia, constata-se que em nenhum momento se argüiu o caráter constritivo das normas comunitárias, com seu efeito impositivo constituindo-se em pacífica conviç̧ão, conforme se depreende da reiterada jurisprudência da Corte do Luxemburgo, em nenhum momento contrariada ou questionada nas jurisdições locais.

3) Efeito Direto - A presente característica decorre da automática integração do direito comunitário às ordens jurídicas internas, sem os mecanismos de incorporaçẩo aplicáveis aos tratados, por exemplo, dispensadas as técnicas de outorga legislativa característica das democracias modernas. Conforma o seu efeito self executing, o que seguramente causa certa espécie à posturas jurídicas mais tradicionais. Resta patente que tal característica não se aplica a tratados e protocolos complementares, que

R. Fac. Direito, Curitiba, a.28, n.28, 1994/95, p. 75-83 
tenham dado origem à comunidade considerada em espécie. O sucesso de um processo de integração não dispensa a convicção social de que a vida comunitária não é algo de estrangeiro, mesmo às administrações locais. É eloqüente, per se, o fato de que $60 \%$ das leis que atualmente compõe o ordenamento jurídico europeu serem de natureza comunitária, em detrimento dos outros $40 \%$ diluídos entre as diversas instâncias político-administrativas nacionais. $\mathrm{O}$ fato de uma violação de direito comunitário poder ser argüida por qualquer jurisdicionável, já perante seus juízes naturais e não só pelos Estados nas instâncias européias, é ainda importante corolário do efeito direto da normas comunitárias. Quanto a este último aspecto, voltaremos a abordá-lo quando do tratamento da uniformidade que também caracteriza a disciplina jurídica vertente.

A efetiva convicção do efeito direto do direito comunitário, cumpre destacar, não foi de fácil formação na experiência européia. A tradição jurídica e o particularismo cultural dos países concernentes criou fortes resistências à proposta, o que gerou exaustiva atuação jurisprudencial da Corte de Justiça do Luxemburgo.

4) Primazia - A característica mais sacrílega de um direito comunitário, sob o ponto de vista da concepção "estatólatra" do direito, é indubitavelmente a que aponta para a sua primazia em relação ao direito interno. A tradicional doutrina que abordou o análogo tema do choque entre o direito internacional e direito interno, através das concepções dualista e monista, estudada à exaustão no direito dos tratados, já não é mais suficiente para fazer face à novicidade das questões engendradas pelo moderno fenômeno da globalização das economias e seus desdobramentos jurídicos. Na França, em especial, verificou-se grande reação à primazia do direito comunitário, motivada seguramente pela arraigada concepção cartesiana dà soberania. Acabou prevalecendo, no entanto, a prevalência do direito comunitário, sob o respaldo do art. 55 da Constituição da Velha República, que estipula: Les traités ou accords régulièrment ratifiés ou approuvés ont, des leur publication, une autorité superieure à celle des lois, sous réserve, pour chaque accord ou traité, de son application par l'autre parti.

Também merece atenção o caso da Itália, onde reiterados arestos da Corte de Cassação consagraram o primado do direito comunitário, apoiados na interpretação extensiva do art. 11 da Constituição de 1946, historicamente destinado a permitir a inclusão do país nas Nações Unidas, no delicado contexto do pós-guerra: Art. ll - L'Italia repudia la guerra come strumento 
di offesa alla libertá degli altri popoli e come mezzo di risoluzione delle controversie internazionali; consente, in condizioni di parità con le altre stati, alle limitazioni de sovranitá necessarie ad un ordinamento che assicure la pace e la giustizia fra le Nazioni; promuove e favorisce le organizzazioni internazionali rivolte a tale scopo.

No atual estágio do iter Mercosul, claro que estamos distantes de tal configuração. O próprio instinto "soberanófilo" do Tratado de Assunção resta expressamente patente em seu art. 16, ao estabelecer que durante 0 período de transição todas as decisões serão tomadas não só por consenso, mas ainda com a presença de todos os Estados partes. Porém, a proporção em que se implementem as liberdades típicas de mercado comum, será imponderável a delegação estatal à autoridade comunitária, para o que se vem designando no modelo europeu, de soberania compartilhada ou complementar. Claro que este foi o mais polêmico e discutido aspecto do direito da integração européia, de certa forma retomado nos recentes debates sobre o Tratado de Maastricht, onde veio à lume o dilema que aflige principalmente os chamados "eurocéticos": como continuar soberanos e unidos?

4) Uniformidade de Interpretação e Aplicação - Merece ainda menção, como característica de um direito comunitário, a uniformidade formal e material de que se deve revestir, sendo para tanto indispensável um aparato ordenador e harmonizador de sua interpretação e aplicação. Também no atual estágio do Mercosul a questão não chega a ser suscitada. O considerado nível light de institucionalização, com o mínimo de órgãos e com o modo consensual e unânime de deliberação previsto pacticiamente, possibilita a existência de aparato de solução de controvérsias dos mais singelos. $\mathrm{O}$ anexo 3 do Tratado de Assunção contempla a negociação direta e o Protocolo de Brasília, em vigor não obstante jamais ter sido posto a prova, estabelece três fases procedimentais: conciliação, consulta e arbitragem. Claro que isto não poderá perdurar quando da transição ao mercado comum, que obrigará a adoção de uma aparato judicial bem mais sofisticado, aliás como preconiza o próprio Tratado de Assunção, ainda que de forma indireta, em seu art. 19. A questão resta em aberto e muitas poderão ser as soluções a partir do heurismo e da fecundidade do pensamento jurídico dos "quatro amigos".

O modelo seguido pelo direito europeu é, a propósito, surpreendente e instigante: valendo-se de um instituto considerado a chave mestra, ou a válvula estabilizadora do todo o direito comunitário, os juízes nacionais,

R. Fac. Direito, Curitiba, a.28, n.28, 1994/95, p.75-83 
que são em última análise os efetivos aplicadores do Direito Comunitário, podem, sempre que a matéria objeto do litígio lhe for pertinente, consultar por via prejudicial a Corte Européia, no Luxemburgo, para que ela pronuncie a correta interpretação da norma comunitária que deve incidir sobre o caso em concreto. $\mathrm{O}$ ineditismo do julgamento por via prejudicial nos sistemas judiciais dos países-Mercosul, bem como os princípios da independência e livre convicção da magistratura que adotamos, seguramente nos distanciam em muito de tal solução. Tal julgamento por via prejudicial, com a consulta prévia feita pelo juiz singular ou colegiado, em busca de um prius logico que deve conformar a sentença, por mais extraordinário que possa parecer, já é aplicado corriqueiramente na União Européia, conforme ordena o art. 177 do Tratado de Roma que estabelece, já em sua versão oficial para a língua portuguesa, fruto da adesão de Portugal à Europa:

"O Tribunal de Justiça é competente para decidir, a título prejudicial:

a) Sobre a interpretação do presente Tratado;

b) Sobre a validade e interpretação dos actos adoptados pelas Instituições da Comunidade;

c) Sobre a interpretação dos estatutos dos organismos criados por um acto do Conselho, desde que estes estatutos o prevejam.

Sempre que uma questão desta natureza seja suscitada perante qualquer órgão jurisdicional de um dos Estados-membros, esse órgão pode, se considerar que uma decisão sobre essa questão é necessária ao julgamento da causa, pedir ao Tribunal de Justiça que sobre ela se pronuncie.

Sempre que uma questão desta natureza seja suscitada em processo pendente perante um órgão jurisdicional nacional cujas decisões não sejam susceptíveis de recurso judicial previsto no direito interno, esse órgão é obrigado a submeter a questão ao Tribunal de Justiça".

Certamente a parte final do dispositivo, que constrange à via prejudicial em casos de julgamentos nacionais de última instância ("... tale giurisdizione é tenuta a...", no texto original do Tratado de Roma) é a que mais estupefaz e intriga a nossa visão latino-americana do exercício da jurisdição.

A definição das características de um direito comunitário em abstrato e da tipologia de suas normas, sem pretender exaurir o estudo preliminar 
da matéria, propõe-se a fazer ver a abrangência do tema, bem como as ingentes dificuldades de sua implantação.

Os ciclópicos obstáculos que se devem superar em processos de integração demonstram, com clareza didática, que tais projetos se destinam à sociedades suficientemente maduras, dispostas aos desafios e ávidas do futuro.

R. Fac. Direito, Curitiba, a.28, n.28, 1994/95, p. 75-83 